\title{
Estimulação Precoce na Educação Infantil: um estudo psicométrico.
}

\author{
Carolina Cardoso, 1 ; Leandra Fernandes Procópio 2 .; Marcos \\ Procópio, 3
}

\section{Resumo}

A Educação Especial tem sido uma modalidade de ensino em crescente debate no meio educacional, porém tem se verificado reduzida prática efetiva em contexto escolar. Reconhecendo a importância da estimulação precoce na educação infantil e tendo como marco legal as Diretrizes Educacionais sobre Estimulação Precoce publicado pelo MEC em 1995, foi desenvolvido um estudo bibliométrico de cunho quantitativo e qualitativo no periódico científico digital brasileiro da Scielo, em busca de artigos que apresentassem dados de intervenções realizadas em contexto da Educação Infantil junto à crianças que necessitam de estimulação precoce. A fim de verificar o desenvolvimento de pesquisas e ações decorridas entre o período de 1995 a 2016 foram utilizadas como palavras geradoras os termos: "estimulação essencial", onde encontrou-se 1 artigo; "estimulação precoce" 6 artigos e "intervenção precoce" 29. Após a leitura ampla foram

1

Licenciada em Matemática pela Universidade Federal de Goiás, Regional Catalão; Pedagoga pela Faculdade Albert Einstein; Especialista em Educação Infantil pela Universidade Federal de Goiás, Regional Catalão. e-mail: karolcardoso.r@gmail.com

2

Docente da Unidade Especial de Educação da Universidade Federal de Goiás Regional Catalão. Pedagoga (PUC Goiás), Mestre em Psicologia Escolar pela Universidade de Coimbra, Doutorado em Educação pela Universidade de Aveiro. Doutorado financiado pela Fundação Ciência e Tecnologia / Portugal. e-mail: leandracprocopo@gmail.com

3

Docente da Unidade Especial de Educação da Universidade Federal de Goiás - Regional Catalão. Físico (PUC Goiás), Mestre em Educação, Ciências e Matemática Universidade Federal de Goiás, Doutorado em Educação pela Pontifícia Universidade Católica de Goiás. email: quanticis@gmail.com 
selecionados 13 artigos que atendiam aos critérios previamente estabelecidos de abordagem da estimulação precoce como um programa voltado a crianças que apresentam algum tipo de comprometimento que a leve a ser público álvo da Educação Especial. Da leitura crítica e aprofundada destes artigos foi possível observar um intervalo de oito anos entre a primeira publicação e as Diretrizes do MEC, além de que 11 dos trabalhos trazem a estimulação precoce numa perspectiva médica em detrimento da escolar e apenas 2 trazem orientações para que os estudos realizados sejam estentidos às escolas. $\mathrm{Na}$ análise qualitativa dos trabalhos emergiram a importância de ações e práticas de estimulação vivenciadas pela família tais como o toque e os cuidados básicos e afetivos, reconhecendo a importância do acesso e permanência da criança no ambiente escolar e do papel do professor como estimulador precoce. Através das intervenções realizadas pelo professor estimulador precoce e pela interação e socialização entre crianças com e sem deficiência, o seu desenvolvimento poderá ocorrer efetivamente minimizando os efeitos a longo prazo de um comprometimento cognitivo e físico na criança. Podemos assim perceber que são poucas as pesquisas realizadas pelos professores e/ou profissionais que se envolvem diretamente com esse público dentro das escolas de educação infantil evidenciando a necessidade de garantir formação incial e continuada para os profissionais que atendem crianças de zero a três anos de idade, e de lhes capacitar para que possam fazer parte das equipes multidisciplinares de intervenção para a estimulação precoce e implementar as diretrizes propostas pelo MEC.

Palavras Chave: estimulação precoce1; intervenção precoce2; educação infantil3. 